\title{
Do Learning and Study Strategies Predict Success in Hybrid- Online Physical and Occupational Therapist Education?
}

\author{
Evan M. Pucillo \\ University of St. Augustine for Health Sciences, epucillo@usa.edu \\ Ellen Lowrie Black \\ Liberty University, elblack@liberty.edus
}

Follow this and additional works at: https://nsuworks.nova.edu/ijahsp

Part of the Occupational Therapy Commons, Physical Therapy Commons, and the Scholarship of Teaching and Learning Commons

\section{Recommended Citation}

Pucillo EM, Black EL. Do Learning and Study Strategies Predict Success in Hybrid-Online Physical and Occupational Therapist Education?. The Internet Journal of Allied Health Sciences and Practice. 2021 Jan 01;19(3), Article 1.

This Manuscript is brought to you for free and open access by the College of Health Care Sciences at NSUWorks. It has been accepted for inclusion in Internet Journal of Allied Health Sciences and Practice by an authorized editor of NSUWorks. For more information, please contact nsuworks@nova.edu. 


\title{
Do Learning and Study Strategies Predict Success in Hybrid-Online Physical and Occupational Therapist Education?
}

\begin{abstract}
Purpose: An understanding of the learning strategies most accurately predictive of success has become increasingly important as health professional education programs scale the utilization of online learning in the wake of COVID-19. The purpose of this study was to examine the predictive relationship between The Learning and Study Strategies Inventory (LASSI) and cumulative professional GPA (cPGPA) in hybrid-online physical (PT) and occupational therapist (OT) education. Methods: A convenience sample collected N=149 entry-level PT and OT students from three campuses across Florida, Texas, and California. A total N(\%) of 89(59.7\%) PT and 60(40.3\%) OT students were included for analysis [48(32.2\%) male; 101(67.8\%) female]. A cross-sectional and predictive correlational study design was utilized. Participants self-administered the LASSI and cPGPA was collected in Spring 2020. Standard multiple linear regression analyses were conducted. Results: Neither the LASSI scales, $\mathrm{R}^{2}=0.05[F(10,138)=0.71, p=0.71]$, nor the LASSI components, $\mathrm{R}^{2}=0.01[F(3,145)=0.56, p=0.64]$, were able to accurately predict cpGPA. These findings contradict many prior studies in health professions education where anxiety, attitude, motivation, test strategies, and time management have been significant predictors. Conclusion: This study should be repeated due to a threat to internal validity, the COVID-19 pandemic, which may have influenced outcomes to an unknown degree. The predictive nature of this measure under more natural conditions remains unknown for this population of learners.
\end{abstract}

\section{Author Bio(s)}

Evan M. Pucillo, PT, DPT, EdD is an Assistant Professor of Physical Therapy at the University of St. Augustine for Health Sciences in St. Augustine, FL where he teaches evidence-based practice and clinical neuroscience.

Ellen Lowrie Black, EdD is a Professor in the School of Education at Liberty University where she is a nationally recognized speaker and author.

\section{Acknowledgements}

The authors would like to acknowledge Dr. Kurt Michael, PhD, of Liberty University, for his contributions to the methodological integrity of this study. We would also like to acknowledge the student participants who donated their time to research and helped to make this work possible. 


\title{
1IJAHSP \\ The Internet Joumnal of Allied Health Sciences and Practice \\ Dedicated to allied health professional practice and education \\ Vol. 19 No. 3 ISSN 1540-580X
}

\section{Do Learning and Study Strategies Predict Success in Hybrid-Online Physical and Occupational Therapist Education?}

\author{
Evan M. Pucillo 1 \\ Ellen Lowrie Black²
}

1. University of St. Augustine for Health Sciences

2. Liberty University

United States

\begin{abstract}
Purpose: An understanding of the learning strategies most accurately predictive of success has become increasingly important as health professional education programs scale the utilization of online learning in the wake of COVID-19. The purpose of this study was to examine the predictive relationship between The Learning and Study Strategies Inventory (LASSI) and cumulative professional GPA (cpGPA) in hybrid-online physical (PT) and occupational therapist (OT) education. Methods: A convenience sample collected $\mathrm{N}=149$ entry-level PT and OT students from three campuses across Florida, Texas, and California. A total $\mathrm{N}(\%)$ of $89(59.7 \%)$ PT and $60(40.3 \%)$ OT students were included for analysis [48(32.2\%) male; 101(67.8\%) female]. A cross-sectional and predictive correlational study design was utilized. Participants self-administered the LASSI and cpGPA was collected in Spring 2020. Standard multiple linear regression analyses were conducted. Results: Neither the LASSI scales, $R^{2}=0.05[F(10,138)=$ $0.71, p=0.71]$, nor the LASSI components, $\mathrm{R}^{2}=0.01[F(3,145)=0.56, p=0.64]$, were able to accurately predict cpGPA. These findings contradict many prior studies in health professions education where anxiety, attitude, motivation, test strategies, and time management have been significant predictors. Conclusion: This study should be repeated due to a threat to internal validity, the COVID-19 pandemic, which may have influenced outcomes to an unknown degree. The predictive nature of this measure under more natural conditions remains unknown for this population of learners.
\end{abstract}

Keywords: Learning strategies, study strategies, physical therapist education, occupational therapist education, online learning, health professional learning

\section{Acknowledgements}

The authors would like to acknowledge Dr. Kurt Michael, $\mathrm{PhD}$ for his contributions to the methodological integrity of this study. We would also like to acknowledge the student participants who donated their time to research and helped to make this work possible.

\section{Funding}

This research did not receive any specific grant funding from agencies in the public, commercial, or not-for-profit sectors. 


\section{INTRODUCTION}

Entry-level physical therapist (PT) and occupational therapist (OT) education programs are experiencing exceptional growth rates and are among the twenty fastest-growing occupations in the nation. ${ }^{1,2}$ It is anticipated that these two health professions will experience growth rates of nearly $30 \%$ in this decade. ${ }^{2}$ The boom of health professional education programs has been met with growing trends toward hybrid-online curricula which include varying degrees of online instruction. ${ }^{3}$ As a result, PT and OT programs have witnessed a shift toward online learning and have become increasingly familiar with hybrid-online instruction. ${ }^{4-6}$

Early in 2020, extraordinary times descended upon educational institutions as the COVID-19 pandemic challenged many aspects of teaching and learning in higher education - students in PT and OT programs were no exception. ${ }^{6}$ The pandemic forced widespread campus closures and thrusted millions of college students to online learning as face-to-face operations were halted to mitigate the spread of disease. ${ }^{4-6}$ This prompted a fundamental change to the framework of higher education with great haste. As a result, many PT and OT programs responded by rapidly implementing online instruction to fulfill the needs of student learning outcomes, accrediting bodies, and federal, state, and local governing agencies. ${ }^{7,8}$ Yet, even prior to COVID-19, health professional education was a rapidly evolving area of higher education. ${ }^{8}$ According to the Commission on Accreditation in Physical Therapy Education (CAPTE), approximately $75 \%$ of PT curricula in the U.S. are now hybrid-online, replacing the more traditional face-toface delivery. ${ }^{8}$ Similarly, the percentage of entry-level OT programs offered in a hybrid-online format reach as high as $90 \% .8,9$

Despite the COVID-19 pandemic, hybrid-online health professional education presents new challenges and opportunities, and certain learning and study strategies may impact academic performance in the online environment. Typically, PT and OT programs include a large portion of hands-on laboratory instruction that focuses on the acquisition and mastery of technique-sensitive psychomotor skills. ${ }^{10}$ Prior evidence from medicine, nursing, and chiropractic education suggests elements of the Learning and Study Strategies Inventory (LASSI) may be significantly related to, and predictive of, academic performance. ${ }^{11-23}$ If scales of the LASSI measurement can accurately predict academic success, the tool may be used to identify students at risk for academic difficulty and offer opportunities to promote retention and progression in rigorous curricula.24,25 Currently, however, an understanding of the LASSI in PT and OT education is poor and reliant upon work conducted in other health professions. ${ }^{24,26,27}$ Therefore, the rapid growth of hybrid-online education in PT and OT curricula necessitates a better understanding of the learning and study strategies able to accurately predict academic performance. ${ }^{24}$

The COVID-19 pandemic has yielded a rapid and dramatic shift toward online learning, and an educational imperative now exists to possess a deeper understanding of the learning and study strategies that are predictive of academic success in this population and setting. The purpose of this study was to examine the predictive relationship between scales and components of the LASSI and cumulative professional GPA (cpGPA) in a hybrid-online PT and OT curriculum. It was hypothesized that the LASSI scales of anxiety, attitude, motivation, and time management, and the LASSI component of will, would accurately predict academic performance.

\section{MATERIALS AND METHODS}

A convenience sample collected $n=153$ first-term PT and OT students engaged in hybrid-online coursework at a large, for-profit, health science university in the U.S. This study included the sampling of first-term Masters of Occupational Therapy (MOT), Doctor of Occupational Therapy (OTD), and Doctor of Physical Therapy (DPT) students enrolled in three campuses across Texas, Florida, and California. All subjects were enrolled in pre-licensure PT or OT professional programs, and the three campuses share curricula among their respective professions. A predictive correlational design was used in this study. IRB approval was obtained for all study procedures. Students were solicited for participation during new student orientation activities and continuously throughout the first two weeks of the Spring 2020 trimester. The Spring 2020 trimester was a traditional 15-week term. Open enrollment concluded on February 2nd 2020 . All subjects acknowledged informed consent prior to enrollment. A small financial incentive ( $\$ 10$ gift card) was provided to the first 150 participants who completed the study procedures.

Informed consent was obtained, and participants were supplied access codes to electronically self-administer the LASSI measurement within the first two weeks of the term. The LASSI is a 60-item self-reported assessment tool based on ten scales of learning and study strategies. ${ }^{28}$ The ten scales include Anxiety (ANX), Attitude (ATT), Concentration (CON), Information Processing (INP), Motivation (MOT), Selecting Main Ideas (SMI), Self-testing (SFT), Test Strategies (TST), Time Management (TMT), and Using Academic Resources (UAR). ${ }^{28}$ The three components are Skill, Will, and Self-Regulation. The Skill component measures INP, SMI, and TST. The Will component measures ANX, ATT, and MOT. The Self-regulation component measures CON, TMT, SFT, and UAR. Overall, the reliability of the LASSI is reported to range from $0.73-0.89 .28$ Test-retest reliability of the tool ranges from 0.72 to $0.86 . .^{29-33}$ Agreement across multiple investigations indicates adequate reliability and measurement stability. ${ }^{11,28,30,32,33}$ 
At the conclusion of the Spring 2020 trimester, cumulative professional GPA (cpGPA) data were extracted for each record meeting inclusion criteria and compiled with LASSI scale and component scores. The outcome variable of cPGPA was defined as the participant's overall GPA calculated by the institutional registrar at the conclusion of the 15-week Spring 2020 trimester. This measure did not include any grades from prior coursework at outside institutions or undergraduate courses and was solely based on professional program GPA for the pre-licensure professional students. Therefore, cpGPA data represent one academic trimester of grades among these pre-licensure professional students. Participants were excluded from final analysis if they were under the age of 18, or have previously dropped, withdrawn, failed, or remediated any first-term class for any reason. LASSI measurements submitted after week 3 of the term were excluded from analysis. This was done to establish temporal precedence between the predictor and outcome variable. A total of three records were removed for not meeting the specified inclusion criteria.

A priori statistical power calculation was performed to determine adequate sample size for ten $(\mathrm{k}=10)$ levels of the predictor variable (LASSI scales $x_{1}-X_{10}$ ) with a medium effect size. ${ }^{34} \mathrm{~A}$ minimum sample size of $n=130$ was required to appropriately power a standard multiple regression and detect statistical significance. ${ }^{34,35} \mathrm{All}$ significance levels were set at 0.05 . Data was entered into IBM SPSS 26 (Armonk, NY, 2019) and screened for errors and outliers. ${ }^{36}$ One outlier was removed for a record with a cPGPA >2 SD from the sample mean. Two separate standard multiple linear regression analyses tested the amount of variance in the outcome variable of cpGPA ( $\left.Y^{\prime}\right)$ that were attributed to fluctuations in the predictor variable of LASSI scale ( $\left.x_{1-10}\right)$ and component scores $\left(x_{11-13}\right)$. Assumptions tests were performed, and the sample conformed to the required characteristics. ${ }^{34,35}$

\section{RESULTS}

A total of $n=149$ student records were analyzed [N\% 89(59.7\%) PT; 60(40.3\%) OT]; [48(32.2\%) male; 101(67.8\%) female]. Descriptive statistics for the sample can be found in Table 1. Mean(SD) CpGPA for the sample population was 3.47(0.3). A comparison of LASSI scale and component scores between gender can be found in Table 1. Table 2 displays the results by academic program. There were no significant differences observed in the LASSI scale or component scores between PT and OT students, except for the LASSI scale of Anxiety, which can be found in Table 2. The mean(SD) Anxiety score for OT students 38.6(25.3) was significantly lower than PT students 49.6(28.5) $(p=0.02)$. The comparison between PT and OT students in mean(SD) scores of the Will component approached significance $(p=0.12)$. The mean(SD) scale of Selecting Main Ideas was also lower in OT students 37.3(25.8) compared to PT students 43.4(26.9), approaching significance $(p=0.16)$. The outcome variable of cPGPA was compared for PT and OT students by inter-quartile range across each scale and component of the LASSI measurement. No significant differences were found, nor were any cut-off scores identified in cpGPA related to LASSI scales or components.

Table 1. Descriptive Statistics of the Sample Population

\begin{tabular}{|l|lcccc|}
\hline \multicolumn{2}{|c}{} & $\begin{array}{c}\text { Total sample } \\
n=149\end{array}$ & $\begin{array}{c}\text { Male } \\
n=48\end{array}$ & $\begin{array}{c}\text { Female } \\
n=101\end{array}$ & Comparison \\
\hline Type & Variable & Mean (SD) & Mean (SD) & Mean (SD) & $p$ value \\
\hline Criterion & cpGPA & $3.47(0.3)$ & $3.45(0.3)$ & $3.48(0.4)$ & 0.59 \\
\hline Predictor & LASSI scale & & & & \\
& Anxiety & $45.2(27.7)$ & $54.9(30.1)$ & $40.5(25.3)$ & $<0.01^{*}$ \\
& Attitude & $62.3(24.6)$ & $56.2(26.5)$ & $65.2(23.2)$ & $<0.05^{*}$ \\
& Concentration & $51.1(24.8)$ & $48.6(26.9)$ & $52.2(23.8)$ & 0.40 \\
& Information Processing & $64.1(24.2)$ & $66.9(22.5)$ & $62.7(25.0)$ & 0.32 \\
& Motivation & $57.0(25.1)$ & $53.4(25.5)$ & $58.4(24.8)$ & 0.29 \\
& Selecting Main Ideas & $41.0(26.5)$ & $43.3(28.9)$ & $39.8(25.4)$ & 0.47 \\
& Self-testing & $58.5(26.3)$ & $59.5(28.1)$ & $58.1(25.6)$ & 0.77 \\
& Test Strategies & $54.3(23.7)$ & $55.7(25.8)$ & $53.6(22.8)$ & 0.61 \\
& Time Management & $61.1(26.1)$ & $53.9(29.3)$ & $64.5(23.8)$ & $<0.05^{*}$ \\
& Using Academic Resources & $57.1(26.6)$ & $54.1(29.4)$ & $58.5(25.3)$ & 0.35 \\
\hline Predictor & LASSI component & & & &
\end{tabular}




\begin{tabular}{|l|llll|}
\hline Skill & $53.1(19.8)$ & $55.3(21.5)$ & $52.1(18.9)$ & 0.35 \\
Will & $54.8(19.3)$ & $54.9(21.6)$ & $54.7(18.2)$ & 0.94 \\
Self-Regulation & $56.9(20.0)$ & $54.0(23.4)$ & $58.3(18.2)$ & 0.22 \\
\hline
\end{tabular}

Note. LASSI scale and component scores are represented out of 100 points; $\mathrm{cpGPA}$ is represented on a 4.0 scale. LASSI = Learning and Study Strategies Inventory; cpGPA = cumulative professional Grade Point Average.

Table 2. Descriptive Statistics by Academic Program

\begin{tabular}{|c|c|c|c|c|}
\hline & & PT & OT & Comparison \\
\hline & & $n=89$ & $n=60$ & \\
\hline Type & Variable & Mean (SD) & Mean (SD) & $p$ value \\
\hline Criterion & CDGPA & $3.48(0.3)$ & $3.45(0.4)$ & 0.51 \\
\hline Predictor & LASSI scale & & & \\
\hline & Anxiety & $49.6(28.5)^{*}$ & $38.6(25.3)$ & $0.02^{*}$ \\
\hline & Attitude & $62.8(24.4)$ & $61.5(25.0)$ & 0.75 \\
\hline & Concentration & $51.9(25.6)$ & $49.8(23.6)$ & 0.61 \\
\hline & Information Processing & $64.9(24.1)$ & $62.9(24.6)$ & 0.63 \\
\hline & Motivation & $57.9(22.6)$ & $55.5(28.5)$ & 0.56 \\
\hline & Selecting Main Ideas & $43.4(26.9)$ & $37.3(25.8)$ & 0.16 \\
\hline & Self-testing & $60.1(27.1)$ & $56.2(25.1)$ & 0.38 \\
\hline & Test strategies & $55.2(23.8)$ & $52.9(23.8)$ & 0.55 \\
\hline & Time management & $61.2(26.8)$ & $61.0(25.2)$ & 0.97 \\
\hline & Using Academic Resources & $56.4(27.0)$ & $58.1(26.3)$ & 0.70 \\
\hline Predictor & LASSI component & & & \\
\hline & Skill & $54.5(19.6)$ & $51.0(20.0)$ & 0.29 \\
\hline & Will & $56.8(18.8)$ & $51.9(19.7)$ & 0.12 \\
\hline & Self-Regulation & $57.4(20.8)$ & $56.3(18.9)$ & 0.74 \\
\hline
\end{tabular}

Note. LASSI = Learning and Study Strategies Inventory; cpGPA = cumulative professional Grade Point Average; PT = Physical Therapy; OT = Occupational Therapy.

The regression model summary for the ability of the ten LASSI scales to predict cpGPA can be found in Table 3 , where $F(10,138)$ $=0.71, p=0.71$. Multiple correlation coefficients were $R=0.22, R^{2}=0.05$, and adjusted $R^{2}=-0.02$. The ten LASSI scale scores only explain $5 \%$ of the variance noted in the outcome variable of cPGPA. Individual LASSI scales and their contribution to the overall regression model can be found in Table 4. The LASSI scales of Test Strategies and Motivation had the highest 3 coefficients and t-ratios and only contributed $25 \%$ and $15 \%$ of the explained variation in this regression model, respectively. Neither of these scales achieved significance; however, Test Strategies approached a significance threshold $(p=0.08)$.

The regression model summary for the ability of the three LASSI components to predict cpGPA can be found in Table 5, where $F(3,145)=0.56, p=0.64$. Multiple correlation coefficients were $\mathrm{R}=0.11, \mathrm{R}^{2}=0.01$, and adjusted $\mathrm{R}^{2}=-0.01$. Individual LASSI components and their contribution to the overall regression model can be found in Table 6. The LASSI component scores of Skill, Will, and Self-regulation only explain $1 \%$ of the variance noted in the outcome variable of cpGPA. No significant predictive correlations were identified. Furthermore, the LASSI component of Will, with the greatest $\beta$ coefficient and t-ratio, only contributed $12 \%$ to the explanation of cpGPA for this regression model $(p=0.38)$.

Table 3. Standard Regression Model Summary of LASSI scales

\begin{tabular}{|l|c|c|c|c|c|}
\hline Predictor Variables & $\mathrm{R}$ & $\mathrm{R}^{2}$ & Adj. $\mathrm{R}^{2}$ & SEE & Durbin-Watson \\
\hline ANX, ATT, CON, INP, MOT, & 0.22 & 0.05 & -0.02 & 0.34 & 1.97 \\
SMI, SFT, TST, TMT, UAR & & & & & \\
\hline
\end{tabular}

Note. Multiple correlation coefficients represented include $\mathrm{R}=$ correlation coefficient; $\mathrm{R}^{2}=$ amount of explained variance; and Adjusted $\mathrm{R}^{2} ; \mathrm{SEE}=$ Standard error of the estimate. ANX = Anxiety; $\mathrm{ATT}=$ Attitude; $\mathrm{CON}=$ Concentration; INP = Information Processing; MOT = Motivation; SMI = Selecting Main Ideas; SFT = Self-testing; $T M T$ = Time Management; UAR = Using Academic Resources. 
Table 4. Contribution of the LASSI scales to cPGPA

\begin{tabular}{|l|ccccccc|}
\hline \multicolumn{2}{|c}{} & \multicolumn{1}{|c}{} & \multicolumn{3}{c}{ Correlation } \\
\hline Predictor Variable & $B$ & $S E$ & $\beta$ & $t$ & Sig. & Zero-order & Partial \\
\hline Anxiety & 0.00 & 0.10 & -0.04 & -0.34 & 0.74 & 0.06 & -0.03 \\
Attitude & -0.001 & 0.001 & -0.06 & -0.53 & 0.60 & 0.02 & -0.05 \\
Concentration & -0.001 & 0.002 & -0.04 & -0.34 & 0.73 & 0.01 & -0.03 \\
Information Processing & -0.001 & 0.002 & -0.04 & -0.41 & 0.70 & -0.03 & -0.03 \\
Motivation & $\mathbf{0 . 0 0 2}$ & $\mathbf{0 . 0 0 1}$ & $\mathbf{0 . 1 5}$ & $\mathbf{1 . 1 9}$ & $\mathbf{0 . 2 4}$ & $\mathbf{0 . 1 1}$ & $\mathbf{0 . 1 0}$ \\
Selecting Main Ideas & -0.001 & 0.002 & -0.09 & -0.73 & 0.47 & 0.02 & -0.06 \\
Self-testing & -0.001 & 0.002 & -0.07 & -0.61 & 0.54 & -0.03 & -0.05 \\
Test Strategies & $\mathbf{0 . 0 0 3}$ & $\mathbf{0 . 0 0 2}$ & $\mathbf{0 . 2 5}$ & $\mathbf{1 . 7 9}$ & $\mathbf{0 . 0 8}$ & $\mathbf{0 . 1 5}$ & $\mathbf{0 . 1 5}$ \\
Time Management & 0.00 & 0.002 & -0.22 & -0.22 & 0.83 & 0.01 & -0.02 \\
Using Academic Resources & -0.0003 & 0.001 & -0.03 & -0.31 & 0.98 & 0.02 & -0.003 \\
\hline
\end{tabular}

Note. Statistics represented are unstandardized regression coefficient (B), standard error (SE), standardized regression coefficient beta $(\beta)$, significant test $(t), p$ value (Sig.), and zero-order and partial correlation. cpGPA $=$ cumulative professional GPA.

Table 5. Standard Regression Model Summary for LASSI components

\begin{tabular}{|l|c|c|c|c|c|}
\hline Predictor Variables & $\mathrm{R}$ & $\mathrm{R}^{2}$ & $\mathrm{Adj} . \mathrm{R}^{2}$ & $\mathrm{SEE}$ & Durbin-Watson \\
\hline Skill, Will, Self-Regulation & 0.11 & 0.011 & -0.01 & 0.34 & 2.03 \\
\hline
\end{tabular}

Note. Multiple correlation coefficients represented include $\mathrm{R}=$ correlation coefficient; $\mathrm{R}^{2}=$ amount of explained variance; and Adjusted $\mathrm{R}^{2}$; SEE = Standard error of the estimate.

Table 6. Contribution of the LASSI components to cPGPA

\begin{tabular}{|c|c|c|c|c|c|c|c|}
\hline \multicolumn{8}{|c|}{ Correlation } \\
\hline Predictor Variable & $B$ & $S E$ & $\beta$ & $t$ & Sig. & Zero-order & Partial \\
\hline Skill & 0.000 & 0.002 & 0.03 & 0.19 & 0.85 & 0.06 & 0.02 \\
\hline Will & 0.002 & 0.002 & 0.12 & 0.96 & 0.38 & 0.09 & 0.08 \\
\hline Self-Regulation & -0.001 & 0.002 & -0.09 & -0.76 & 0.45 & 0.003 & -0.06 \\
\hline
\end{tabular}

Note. Statistics represented unstandardized regression coefficient (B), standard error (SE), standardized regression coefficient beta $(\beta)$, significant test $(\mathrm{t}), \mathrm{p}$ value (Sig.), and zero-order and partial correlation.

\section{DISCUSSION}

To date, much study has been conducted using the LASSI measurement in health professional education. ${ }^{14-26}$ Yet, this study is the first of its kind to report on the predictive nature of the LASSI in PT and OT education. This study focused entirely on PT and OT learners engaged in a pre-licensure hybrid-online education program. In this study, none of the ten scales or three components of the LASSI were able to accurately predict future academic success in PT and OT learners. The results of this study are mostly incongruent with prior findings from health professional education, particularly in medicine and nursing. ${ }^{14-16,18-23}$ Historically, the LASSI scales of anxiety, attitude, concentration, motivation, time management, and test strategies have continually emerged as learning strategies linked to success in health professional education.18,21-23,37-41 Indeed, in this sample, attitude, motivation, and scales involving cognitive processing were among the highest-rated for PT and OT students. These factors support recent evidence from Aguilera-Hermida that examined attributes of successful online learning post-COVID-19.42 Overall, both PT and OT students experienced higher than expected levels of anxiety, on which the COVID-19 pandemic may have had a significant influence. There may be an important connection to be uncovered surrounding learning strategies such as attitude, motivation, and anxiety as students navigate the intersection between online learning and COVID-19 restrictions. Despite broad inconsistencies with prior findings, this study furthers the conversation in this emerging topic and may assist future investigations with avoiding pitfalls in design, methodology, and the control of confounding factors.

One explanation for the discrepancy in findings between this and prior studies is inherent differences in curriculum and instruction across health professional education programs. There may be fundamental differences between how PT and OT students are 
instructed when compared to medicine, nursing, and pharmacy. Therefore, drawing comparisons to prior findings in the literature from other health professions may not be contextually appropriate. Much of PT and OT professional education depends on the acquisition and mastery of psychomotor skill and technique-sensitive therapeutic treatments. ${ }^{6,10}$ As such, these educational programs are typically reliant upon hands-on laboratory instruction where students practice therapeutic rehabilitation techniques. 6,8 Laboratory instruction may be under represented in other education programs and is one possible explanation for differences in the study outcomes. On the other hand, chiropractic education may share many similarities to PT and OT education given the degree of hands-on psychomotor components of laboratory learning. 19,20,40 However, previous findings on the predictive nature of the LASSI in chiropractic students from Schutz et al are more consistent with those from the medical profession than this study. ${ }^{19,20}$ It is possible that the LASSI may not be appropriate for this population of learners, or in hybrid-online environments. Perhaps, the LASSI may be more relevant to traditional face-to-face education programs or in programs where psychomotor hands-on laboratory skills are not a defining characteristic.

\section{Limitations}

There are several limitations to this study that may have impacted outcomes. Mainly, threats existed to the internal validity due to the COVID-19 pandemic. As a result, broad generalizations of the findings from this study are cautioned. Participants in this study were forced to transition from hybrid-online coursework into fully online coursework at week 9 of the trimester - slightly over halfway through the 15-week term. Variables measured may have been impacted by this event, thus, altering the observations to an unknown degree. Additionally, although the three campuses sampled have a shared curriculum, instructor variation may have influenced grading, and subsequently the outcome variable of cpGPA. Controlling for this heterogeneity lay beyond the scope of this study and is difficult to control in educational research.

Furthermore, PT and OT students were treated as an aggregate sample under the assumptions of adult learning theory. There may be flaws to these assumptions, and PT and OT students should be measured and analyzed separately in future studies. Although there may be similarities between curricula, PT and OT students may preferentially select differing learning strategies for a variety of reasons. This was evidenced by differences between PT and OT students in Anxiety, Selecting Main Ideas, and SelfRegulation. Indeed, OT students and females performed lower on the LASSI scales of Anxiety and Selecting Main Ideas when compared to PT students in this sample. However, this may potentially be explained by a smaller sample of OT students, or that females were generally over represented in both samples in this study, and not necessarily representative of the broader population. Lastly, participants may have previously self-administered the LASSI in undergraduate study and this interaction may have contaminated the results collected. Previous encounters with the LASSI measurement were not controlled for in this study but should be considered in future exclusion criteria.

\section{Recommendations for Future Studies}

Future studies should consider examining the LASSI measurement across a variety of outcome variables in addition to GPA. 23,25,26,37 For example, national licensure examination scores and academic retention data may be responsive to the LASSI. Other predictors should also be explored, as the LASSI may not have a firm theoretical application to this population of learners in the online or hybrid-online environment. ${ }^{11,24,36,42}$ To further understand its applicability in health professional students, larger studies with robust methods and controls would be needed to examine the diagnostic accuracy and measures of responsiveness of the LASSI. Furthermore, the outcome variable of cpGPA has certain limitations. ${ }^{16}$ One possible limitation to using GPA is the likelihood that variation in grading may have occurred. This sample was obtained from three campuses in three different states and may have been influenced by the interrater reliability between numerous instructors with varying degrees of educational experience. However, accounting for the degree to which this occurred lay outside the scope of this study. Finally, GPA tends to occur with a reduced range, where the majority of recorded scores fall between 3.0 and 4.0. In turn, this may have impacted the ability of a regression models to detect statistical significance.

\section{CONCLUSIONS}

Undeniable trends exist toward the widespread utilization of online learning in health professional education. ${ }^{3,6,8}$ Yet, many aspects of learning for this setting and mode of delivery remain unknown. As health professional education shifts online due to COVID-19 restrictions, this study may provide a valuable framework upon which future investigations may build and refine an approach to further inquiry on this topic. Prior to the COVID-19 pandemic, many health professional education programs were already utilizing online instruction to varying degrees. ${ }^{8}$ However, the COVID-19 pandemic has since expedited the adoption of online learning for many institutions, including PT and OT programs. ${ }^{6,42}$ Online learning may present unique challenges for students in programs that require acquisition and mastery of technique-sensitive hands-on skills. ${ }^{6}$ Therefore, as online and hybrid-online programs continue to expand in their scale and scope, it is imperative to further our understanding of learning and study strategies in health 
professional learners. ${ }^{24}$ In a post-COVID-19 world, a more complete knowledge of this topic may help prevent academic difficulty and promote retention/progression. As such, it would prove valuable to professional educators, learners, and administrators within this rapidly growing area of education.

\section{REFERENCES}

1. Landry MD, Hack LM, Coulson E, et al. Workforce projections 2010-2020: Annual supply and demand forecasting models for physical therapists across the United States, Phys Ther. 2019;96(1):7180, https://doi.org/10.2522/pti.20150010

2. U.S. Bureau of Labor Statistics. Occupational outlook handbook: Fastest growing occupations 2016-2026; 2019. https://www.bls.gov/ooh/fastest-growing.htm

3. Jensen GM, Nordstrom T, Segal RL, et al. Education research in physical therapy: Visions of the possible. Phys Ther. 2016;96(12):1874-1884. https://doi.10.2522/ptj.20160159

4. Centers for Disease Control and Prevention. Corona Virus Disease 2019 (COVID-19). Accessed on April $28^{\text {th }}, 2020$. Retrieved from: https://www.cdc.gov/coronavirus/2019-ncov/faq.html

5. Gardner L. Covid-19 Has Forced Higher Ed to Pivot to Online Learning. Here Are 7 Takeaways So Far. The Chronicle of Higher Education. March 20th, 2020. https://www.chronicle.com/article/Covid-19-Has-Forced-Higher-Ed/248297

6. Gagnon K, Young B, Bachman T, et al. Doctor of Physical Therapy Education in a Hybrid Learning Environment: Reimagining the Possibilities and Navigating a "New Normal". Phys Ther. 2020;100(8), 1268-77.

7. Commission on the Accreditation in Physical Therapy Education (CAPTE). Response to COVID-19. Accessed on March 13 th $^{\text {h }}$ 2020. http://www.capteonline.org/uploadedFiles/CAPTEorg/Homepage/CAPTEResponsetoCOVID19.pdf

8. Commission on the Accreditation in Physical Therapy Education (CAPTE). Aggregate program data: 2018-2019 physical therapist education programs fact sheets. 2019. http://www.capteonline.org/uploadedFiles/CAPTEorg/About_CAPTE/Resources/Aggregate_Program_Data/Aggregate ProgramData_PTPrograms.pdf

9. Harvison N. Academic Programs Annual Data Report: Academic Year 2017-2018. The American Occupational Therapy Association, Inc. 2018. https://www.aota.org/ /media/Corporate/Files/EducationCareers/Educators/20172018-Annual-Data-Report.pdf

10. Plack MM, Driscoll M. Teaching and learning in Physical Therapy: From classroom to clinic. 2019. Thorofare, NJ: Slack, Inc.

11. Alkhateeb HM, Nasser R. Assessment of learning and study strategies of university students in Qatar using an Arabic translation of the learning and study strategies inventory. Psychological Reports. 2014;114(3): 947-965.

12. Crede M, Kuncel NR. Study habits, skills, and attitudes: The third pillar supporting collegiate academic performance. Perspectives in Psychological Science. 2008;3(6), 425-453. https://doi.10.1111/j.1745-6924.2008.00089.x

13. Griffin R, Mackewn A, Moser E, et al. Do learning and study skills affect academic performance? An empirical investigation. Contemporary Issues in Education Research. 2012;5(2), 109-116. https://eric.ed.gov/?id=EJ1073168

14. Jouhari Z, Haghani F, Changiz T. Assessment of medical students' learning and study strategies in self-regulated learning. Journal of Advances in Medical Education \& Professionalism. 2016;4(2):72-79. https://www.ncbi.nlm.nih.gov/pmc/articles/PMC4827759/

15. Khalil MK, Williams SE, Hawkins H. Learning and study strategies correlate with medical students' performance in anatomical sciences. Anatomical Sciences Education. 2018;11(3):236-242. https://doi.10.1002/ase.1742

16. Khalil MK, Williams SE, Hawkins H. The use of Learning and Study Strategies Inventory (LASSI) to investigate differences between low vs high academically performing medical students. Med Sci Educ. 2019;1-6.

17. Lobb WB, Wilkin NE, McCaffrey DJ, et al. The predictive utility of nontraditional test scores for first-year pharmacy student academic performance. Amer J Pharm Educ. 2006;70(6):128. https://www.ncbi.nlm.nih.gov/pubmed/17332854

18. Norouzinia R, Seidabadi M, Mohammadi R, et al. The relationship between learning and study strategies with students academic performance. Educational Research in Medical Sciences Journal. 2016;5(1):16-23.

19. Schutz CM, Dalton L, Tepe RE. Learning and Study Strategies Inventory subtests and factors as predictors of National Board of Chiropractic Examiners Part 1 examination performance. J Chiropract Educ. 2013;27(1), 5-10. https://doi.10.7899/JCE-D-12-012

20. Schutz CM, Gallagher ML, Tepe RE. (2011). Differences in learning and study strategies inventory scores between chiropractic students with lower and higher grade point averages. J Chiropract Educ. 2001;25(1):5-10. https://www.ncbi.nlm.nih.gov/pmc/articles/pmid/21677867/ 
21. West $\mathrm{C}$, Kurz T, Smith $\mathrm{S}$, et al. Are study strategies related to medical licensing exam performance? Int J Med Educ. 2014:5:199.

22. West C, Sadoski M. Do study strategies predict academic performance in medical school? Med Education. 2011;45(7):696-703. https://doi:10.1111/j.1365-2923.2011.03929.x

23. Zhou Y, Graham L, West C. The relationship between study strategies and academic performance. Int J Med Educ. 2016;7: 324-332. https://doi.10.5116/ijme.57dc.feOf

24. Pucillo EM, Kiernan E, Shotwell MP, et al. Learning Strategies and Academic Difficulty in Occupational and Physical Therapy Online Education. Journal of Occupational Therapy Education. 2020;4(2):5-11.

25. Villarreal V, Martinez A. (2018). Assessing study skills in college students: A review of three measures. Journal of College Student Development. 2018;59(5):629-635.

26. Lee S. Learning and Study Strategies Inventory scores and academic performance of occupational therapy students. Am J Occupational Therapy. 2018;72 (4_Supplement_1). https://doi:10.5014/ajot.2018.72S1-P04020

27. Waite JG, Farkas GJ, Topp KS, et al. Assessing determinants of musculoskeletal anatomy success in first-year physical therapy students. The FASEB Journal. 2019;33(1_supplement), 442-451.

28. Weinstein CE, Palmer DR, Acee TW. Learning and Study Strategies Inventory (LASSI) 3rd Edition. H\&H Publishing Company, Inc. 2016.

29. Deming, MP, Valeri-Gold M, Idleman LS. The reliability and validity of the Learning and Study Strategies Inventory (LASSI) with college developmental students. Literacy Research and Instruction. 1994;33(4):309-318.

30. Flowers LA. Test-retest reliability of the learning and study strategies inventory (LASSI): New evidence. Literacy Research and Instruction. 2003;43(1), 31-46. https://doi.org/10.1080/19388070309558399

31. Flowers LA, Bridges BK, Moore IJ. Concurrent validity of the Learning and Study Strategies Inventory (LASSI): A study of African American precollege students. Journal of Black Studies. 2012;43(2):146-160. https://doi.org/10.1177/0021934711410881

32. Marland JG, Dearlove J, Carpenter J. LASSI: An Australian evaluation of an enduring study skills assessment tool. Journal of Academic Language and Learning. 2015;9(2):A32-A45. https://ro.uow.edu.au/asdpapers/494/

33. Melancon JG, Sanders S, Smith PL. Reliability, structure, and correlates of learning and study strategies inventory scores. Educational and Psychological Measurement. 2002;62(6):1020-1027. https://doi.org/10.1177/0013164402238088

34. Portney LG, Watkins MP. Foundations of research: Application to practice (3rd ed.). F.A. Davis, Inc. 2015.

35. Warner RM. Applied statistics: From bivariate through multivariate techniques ( $2^{\text {nd }}$ ed.). Sage Publications, Inc. 2008.

36. IBM Corp., IBM SPSS Statistics for Windows, Version 26.0. Armonk, NY: IBM Corp. 2019.

37. Jouhari Z, Haghani F, Changiz T. Factors affecting self-regulated learning in medical students: A qualitative study. Medical Education Online. 2015;(20):286-94. https://doi.10.3402/meo.v20.28694

38. Kuo YL. Relationship among study strategies, course grades, and success on the Taiwanese National Physical Therapy Examination. 醫學教育, 2015;19(1):1-10. https://oi.10.6145/jme201501

39. Sleight DA, Mavis BE. Study skills and academic performance among second-year medical students in problem-based learning. Medical Education Online. 2006;11(1), 1-6.

40. Donaldson SF. A comparison of chiropractic students' learning styles based on admission status. [Doctoral dissertation, Walden University]. 2018. https://search.proquest.com/openview/affcb6c22dfd3bc44c655b04ec949931/1?pqorigsite $=$ gscholar \&cbl=18750\&diss $=y$

41. Donker AS, de Boer H, Kostons, D., et al. Effectiveness of learning strategy instruction on academic performance: A meta-analysis. Educational Research Review. 2014;(11), 1-26. https://doi.10.1016/i.edurev.2013.11.002

42. Aguilera-Hermida AP. College students' use and acceptance of emergency online learning due to Covid-19. Int J Educ Research Open. 2020. Jan 1;1. https://doi.org/10.1016/.ijedro.2020.100011 